\title{
Results of surgical repair of atrial septal defects in the middle-aged and elderly
}

\author{
D. E. R ICHMOND ${ }^{1}$, J.B. LOWE, AND B. G. BARRATT-BOYES \\ From the Cardiology Unit and Cardio-Thoracic Surgical Unit, Green Lane Hospital, \\ Auckland, New Zealand
}

\begin{abstract}
Twenty-six patients aged 45 or over at the time of surgical repair of a secundum atrial septal defect have been reviewed with the object of assessing the value of the operation. Pre-operatively 12 were classed as grade IIIA or worse on the basis of their symptoms. There were six deaths in the series, three early and three late. The remaining 20 patients were improved as judged by symptoms, physical examination, and radiographic and electrocardiographic criteria. In 11 patients catheterized pre- and post-operatively, it was found that the pulmonary arterial pressure had fallen following the repair, reaching normal levels in nine. It is concluded that surgical repair of secundum atrial septal defects is of material benefit to patients of this age-group.
\end{abstract}

Although patients with atrial septal defects may have a normal life span during which they are symptom-free, many die prematurely and many more become increasingly symptomatic with age. The average age at death has varied in different series between 36 and 49 years (Roesler, 1934 ; Burrett and White, 1945; Welch and Kinney, 1948 ; Cosby and Griffith, 1949 ; Campbell, Neill, and Suzman, 1957 ; and Davidsen, 1960). A recent study by Markman, Howitt, and Wade (1965) supports the contention of Wood (1962) that most patients will develop symptoms by the sixth decade even though symptom-free before this.

In recent years, repair of atrial septal defect has been practicable with an acceptably low mortality (Barratt-Boyes, 1963). Because it has been our belief that repair of the defect will favourably influence the prognosis in terms of both morbidity and mortality, it has been our practice to advise surgical closure, unless the shunt is diminutive, in all patients with uncomplicated atrial septal defect, including those who are middle-aged. However, it has been suggested that surgery may not benefit the middle-aged or elderly patient with an atrial septal defect (Wolf, Vogel, Pryor, and Blount, 1968 ; Markman et al., 1965); and in an attempt to clarify our own experience we have recently reviewed all our patients aged 45 or more at the time of atrial septal defect repair. It is the purpose of this paper to present the results of this review.

1Present address : c/o Georgetown University Medical Center, 3800 Reservoir Road, N.W.. Washington, D.C. 20007, U.S.A.

\section{METHOD OF STUDY}

Twenty-six patients aged 45 or more have had secun-o dum or sinus-venosus type atrial septal defects re paired since 1957. The group comprises 11 men ando 15 women. Eleven were aged 50 or more at the timeo of operation, and of these six were 55 or older. The@ oldest patient to be operated on was 59 . There were $\Rightarrow$ three hospital and three late deaths in the series and 3 post-mortem examination was undertaken in four of these. The survivors were all re-examined by us and a comparison was made with our pre-operative assessment. Chest radiographs, electrocardiograms, and where possible, cardiac catheterization were performed $\frac{0}{\tilde{N}}$ The duration of follow-up ranged from 4 months tox 9 years (Fig. 1), with a mean of 4 years 2 months.

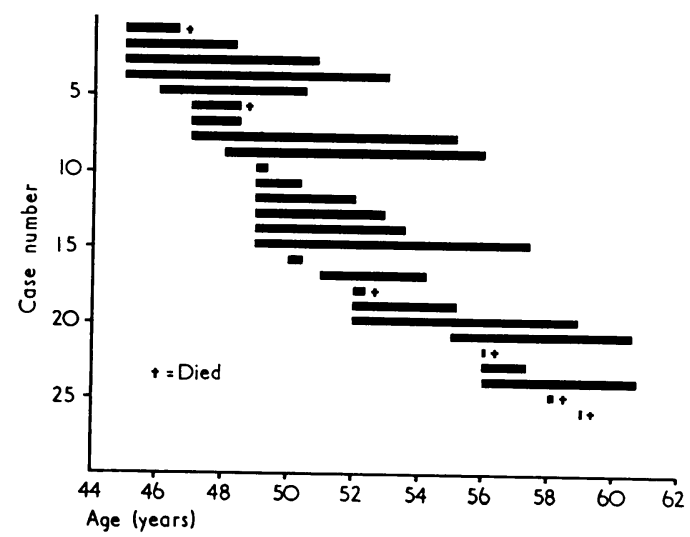

FIG. 1. Duration of follow-up of 26 patients following closure of atrial septal defect. 


\section{PRE-OPERATIVE DATA}

Twenty-three of the patients were referred because of decreasing exercise tolerance. Three denied effort dyspnoea, but two of these were referred because of palpitations. Only one was symptom-free.

The relative frequency of presenting symptoms is illustrated in Figure 2. On the basis of Donald, Bishop, and Wade's (1954) modification of the New York Heart Association clinical grades, three patients were classified grade I, eight grade II, seven grade IIIA, six grade IIIB, and two grade IV.

When first seen five patients were in frank congestive heart failure, and in two others the jugular venous pressure was significantly raised. The systolic lift over the right ventricle was assessed as slight in 13 , moderate in 10 , and considerable in two. In three a systolic pulmonary artery lift was palpable. An ejection click in the pulmonary area was audible in 11. A systolic ejection murmur in the pulmonary area was not a constant finding, being present in only 20 of the 26. In three no murmurs were audible, and in the remaining two, one of whom was found to have

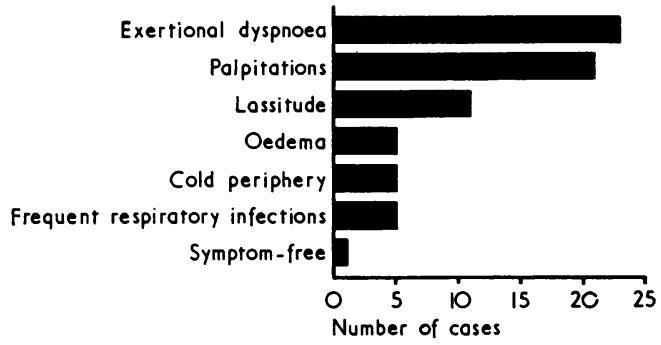

FIG. 2. Relative frequency of symptoms with which patients presented. associated mitral incompetence due to a ruptured posterior cord, there was an apical pansystolic murmur. The second heart sound was widely split and fixed in 18 , abnormally widely split but varying with respiration in five, and of uncertain behaviour in three. Tricuspid diastolic murmurs were heard in 11 and an early diastolic murmur in the pulmonary area attributed to pulmonary incompetence was noted in one. The murmur of tricuspid incompetence was present in two patients.

On radiological examination, cardiac enlargement was shown in 24, whilst in 22 the lung fields were convincingly plethoric.

Standard 12-lead electrocardiograms revealed the presence of a partial right bundle-branch block pattern in 21 and a complete right bundle-branch block pattern in four. The remaining patient showed a left bundle-branch block pattern. Evidence of right ventricular hypertrophy as judged by the $R: S$ ratio in lead $V_{1}$ was present in 20. Ten patients had an arrhythmia. In two this consisted of frequent ventricular ectopic beats, seven were in atrial fibrillation or flutter, and one had a supraventricular tachycardia with a 2:1 ventricular response. The mean QRS axis in the frontal plane was less than $-90^{\circ}$ in three patients, normal (i.e., between $-30^{\circ}$ and $+110^{\circ}$ ) in 19 , and greater than $+110^{\circ}$ in two. In two the vector was indeterminate.

All but case 12 underwent cardiac catheterization pre-operatively. The relevant catheter data are summarized in Tables I and II. (Table II comprises those patients in whom post-operative studies were also undertaken.) All patients had a left-to-right shunt at atrial level, the pulmonary to systemic flow ratio (Qp/Qs) ranging from 1.6 to 6.5. In 18, systolic pulmonary artery pressure was elevated to over $30 \mathrm{~mm}$. $\mathrm{Hg}$, and in four of these it was above $60 \mathrm{~mm} . \mathrm{Hg}$. The pulmonary vascular resistance in all but eight patients was less than 2 resistance units; and in only two was the resistance as high as 5 units.

T A B L E I

CATHETER DATA OF PATIENTS WITH ATRIAL SEPTAL DEFECTS STUDIED ONLY PREOPERATIVELY (ZERO LEVEL AT ANGLE OF LOUIS)

\begin{tabular}{|c|c|c|c|c|c|c|c|}
\hline Case & Sex & Age & $\begin{array}{l}\text { Functional } \\
\text { Grading }\end{array}$ & $\begin{array}{l}\text { Qp/Qs } \\
\text { Ratio }\end{array}$ & $\begin{array}{c}\text { Mean R.A. } \\
\text { Pressure } \\
\text { (mm. Hg) }\end{array}$ & $\begin{array}{c}\text { P.A. Pressure } \\
\text { (mm. Hg) } \\
\text { Phasic }\end{array}$ & $\begin{array}{c}\text { Pulmonary } \\
\text { Vascular } \\
\text { Resistance } \\
\text { (resistance } \\
\text { units) }\end{array}$ \\
\hline $\begin{array}{r}1 \\
2 \\
6 \\
7 \\
10 \\
11 \\
14 \\
16 \\
17 \\
19 \\
22 \\
23 \\
25 \\
26\end{array}$ & $\begin{array}{c}\mathbf{M} \\
\mathbf{M} \\
\mathbf{F} \\
\mathbf{F} \\
\mathbf{F} \\
\mathbf{F} \\
\mathbf{F} \\
\mathbf{F} \\
\mathbf{F} \\
\mathbf{F} \\
\mathbf{M} \\
\mathbf{M} \\
\mathbf{M} \\
\mathbf{F}\end{array}$ & $\begin{array}{l}45 \\
45 \\
47 \\
47 \\
49 \\
49 \\
49 \\
49 \\
51 \\
52 \\
56 \\
56 \\
58 \\
59\end{array}$ & $\begin{array}{l}\text { II } \\
\text { I } \\
\text { II } \\
\text { IV } \\
\text { IIIA } \\
\text { IIIB } \\
\text { II } \\
\text { IIIB } \\
\text { IIIB } \\
\text { IIIA } \\
\text { IIIB } \\
\text { I } \\
\text { IIIA } \\
\text { II }\end{array}$ & $\begin{array}{l}1 \cdot 7 \\
2 \cdot 25 \\
3 \\
4 \cdot 5 \\
2 \cdot 4 \\
2 \cdot 5 \\
1 \cdot 9 \\
5 \\
2 \\
2 \cdot 4 \\
3 \\
2 \cdot 1 \\
2 \cdot 3 \\
1 \cdot 6\end{array}$ & $\begin{array}{r}2 \\
-2 \\
-1 \\
-5 \\
-2 \\
4 \\
2 \\
2 \\
2 \\
1 \\
2 \\
2 \\
3 \\
3\end{array}$ & $\begin{array}{l}62 / 28 \\
20 / 7 \\
38 / 23 \\
86 / 24 \\
17 / 4 \\
40 / 15 \\
25 / 7 \\
28 / 10 \\
42 / 20 \\
29 / 9 \\
35 / 12 \\
30 / 8 \\
40 / 15 \\
60 / 24\end{array}$ & $\begin{array}{rl} & 3.6 \\
1 & 1.9 \\
& * \\
< & 1 \\
2.5 \\
< & 1 \\
2 & 1.6 \\
& 1 \\
1 \\
< & 1 \\
2.2 \\
5.2\end{array}$ \\
\hline
\end{tabular}

* Not calculable on available data.

Case 12 was not catheterized preoperatively and refused catheterization at follow-up. Shunts calculated on oxygen saturation data. 
T A B L E I I CATHETER DATA OF 11 PATIENTS CATHETERIZED BEFORE AND AFTER OPERATION (ZERO LEVEL AT ANGLE OF LOUIS)

\begin{tabular}{|c|c|c|c|c|c|c|c|c|c|c|c|c|c|c|c|}
\hline \multirow[t]{2}{*}{ Case } & \multirow{2}{*}{$\begin{array}{c}\text { Interval } \\
\text { between } \\
\text { Catheter- } \\
\text { ization } \\
\text { (months) }\end{array}$} & \multirow[t]{2}{*}{ Sex } & \multirow[t]{2}{*}{ Age } & \multicolumn{2}{|c|}{$\begin{array}{c}\text { Functional } \\
\text { Grade }\end{array}$} & \multicolumn{2}{|c|}{$\begin{array}{l}\text { Cardio- } \\
\text { thoracic } \\
\text { Ratio }\end{array}$} & \multicolumn{2}{|c|}{ Qp/Qs Ratio } & \multicolumn{2}{|c|}{$\begin{array}{c}\text { Mean } \\
\text { R.A. } \\
\text { Pressure }\end{array}$} & \multicolumn{2}{|c|}{$\begin{array}{c}\text { P.A. Pressure } \\
\text { (mm. Hg) } \\
\text { Phasic }\end{array}$} & \multicolumn{2}{|c|}{ P.A. Resistance } \\
\hline & & & & Pre & Post & Pre & Post & Pre & Post & Pre & Post & Pre & Post & Pre & Post \\
\hline $\begin{array}{r}3 \\
4 \\
5 \\
8 \\
9 \\
13 \\
15 \\
18 \\
20 \\
21 \\
24\end{array}$ & $\begin{array}{r}8 \\
24 \\
30 \\
24 \\
12 \\
48 \\
24 \\
4 \\
12 \\
8 \\
60\end{array}$ & $\begin{array}{c}\mathbf{M} \\
\mathbf{F} \\
\mathbf{F} \\
\mathbf{M} \\
\mathbf{M} \\
\mathbf{F} \\
\mathbf{F} \\
\mathbf{M} \\
\mathbf{F} \\
\mathbf{F} \\
\mathbf{F}\end{array}$ & $\begin{array}{l}45 \\
45 \\
46 \\
47 \\
48 \\
49 \\
49 \\
52 \\
52 \\
55 \\
56\end{array}$ & $\begin{array}{l}\text { I } \\
\text { II } \\
\text { IIIA } \\
\text { IIIB } \\
\text { II } \\
\text { II } \\
\text { IIIA } \\
\text { IV } \\
\text { IIIA } \\
\text { IIIA } \\
\text { IIIB }\end{array}$ & $\begin{array}{l}\text { I } \\
\text { I } \\
\text { I } \\
\text { I } \\
\text { I } \\
\text { I } \\
\text { I } \\
\text { D } \\
\text { II } \\
\text { I } \\
\text { IIIA }\end{array}$ & $\begin{array}{l}0.51 \\
0.6 \\
0.69 \\
0.60 \\
0.62 \\
0.6 \\
0.71 \\
0.6 \\
0.61 \\
0.61 \\
0.62\end{array}$ & $\begin{array}{l}0.51 \\
0.56 \\
0.59 \\
0.53 \\
0.52 \\
0.6 \\
0.61 \\
0.57 \\
0.56 \\
0.52 \\
0.60\end{array}$ & $\begin{array}{l}2 \cdot 25 \\
2.96 \\
2 \cdot 5 \\
2 \\
3 \cdot 5 \\
2 \cdot 4 \\
3 \cdot 1 \\
3 \\
3 \\
6 \cdot 5 \\
1 \cdot 7\end{array}$ & $\begin{array}{l}\bar{Z} \\
1 \cdot 8 \\
\overline{1} \\
\bar{Z} \\
\overline{1 \cdot 3} \\
1 \cdot 3 \\
1 \cdot 2\end{array}$ & $\begin{array}{r}-1 \\
4 \\
13 \\
1 \\
-2 \\
4 \\
3 \\
5 \\
-2 \\
3 \\
-2\end{array}$ & $\begin{array}{c}1 \cdot 5 \\
-3 \\
5 \\
-3 \\
-3 \\
3 \\
-4 \\
-5 \\
1 \cdot 5 \\
-2 \cdot 5 \\
-2\end{array}$ & $\begin{array}{l}22 / 5 \\
45 / 14 \\
54 / 22 \\
56 / 22 \\
50 / 10 \\
41 / 18 \\
66 / 24 \\
50 / 10 \\
33 / 12 \\
45 / 15 \\
65 / 25\end{array}$ & $\begin{array}{l}16 / 5 \\
20 / 8 \\
33 / 10 \\
23 / 8 \\
28 / 14 \\
25 / 10 \\
22 / 6 \\
25 / 6 \\
28 / 18 \\
22 / 10 \\
37 / 17\end{array}$ & $\begin{array}{l}1 \\
1.9 \\
1.4 \\
3.3 \\
1.4 \\
0.6 \\
4 \\
1 \cdot 3 \\
1.4 \\
1 \\
5 \cdot 3\end{array}$ & $\begin{array}{l}1 \\
1.8 \\
1.4 \\
2 \cdot 25 \\
1 \\
0.75 \\
3.5 \\
1.6 \\
1.9 \\
1.5 \\
4.8\end{array}$ \\
\hline
\end{tabular}

ANATOMY OF THE DEFECTS

Twenty-four patients had secundum type atrial septal defects. In addition one had moderately severe tricuspid regurgitation; another, associated mitral incompetence due to a ruptured posterior cord; and four, associated partial anomalous pulmonary venous drainage.

In two there was a sinus venosus type defect, and in one of these a persistent left superior vena cava was present.

\section{SURGICAL TECHNIQUE}

The repair was performed using the atrial well (Kirklin, Ellis, and Barratt-Boyes, 1956) in 22 patients while cardiopulmonary bypass was used in four. The defect was closed by direct suture in six and a prosthetic patch of uncompressed polyvinyl alcohol (Ivalon) sponge was used in the remainder. In the patient with a sinus venosus type defect and a persistent left superior vena cava (case 22) a complete correction using an internal patch was impracticable because of the smallness of the right superior vena cava. Complete correction was, however, obtained by atrioseptopexy following ligation of the small right superior vena cava above the highest anomalous vein (Williams and Barratt-Boyes, 1959). The other patient with a sinus venosus type defect (case 17) also presented a problem in repair. At operation the atrial defect was found to be large, with the usual anomalous drainage of both right upper and middle lobe pulmonary veins into the superior vena cava. In the course of closure with a prosthetic patch a tear in the superior vena cava required repair. It became obvious that in the post-operative period the superior vena cava now drained to the left atrium. At reoperation using heart-lung bypass the prosthetic patch was found to be occluding the lower end of the superior vena cava. This was corrected, and a satisfactory result, including correction of the anomalous pulmonary venous drainage, achieved.
T A B L E I I I

ANALYSIS OF DEATHS FOLLOWING REPAIR OF A.S.D. $\frac{\overparen{D}}{\overparen{D}}$

\begin{tabular}{|c|c|c|c|c|c|}
\hline \multicolumn{3}{|c|}{ Hospital Deaths } & \multicolumn{3}{|c|}{ Late Deaths } \\
\hline Case & $\begin{array}{l}\text { Cause } \\
\text { of } \\
\text { Death }\end{array}$ & $\begin{array}{c}\text { Period } \\
\text { following } \\
\text { Operation }\end{array}$ & Case & $\begin{array}{c}\text { Cause } \\
\text { of } \\
\text { Death }\end{array}$ & $\begin{array}{l}\text { Period } \\
\text { following } \\
\text { Operation }\end{array}$ \\
\hline 22 & Sudden death & 8 hours & 18 & Sudden death & 4 month \\
\hline 26 & $\begin{array}{l}\text { Massive } \\
\text { haemothorax }\end{array}$ & & 1 & $\begin{array}{l}\text { Myocardial } \\
\text { failure }\end{array}$ & \\
\hline 25 & $\begin{array}{l}\text { Myocardial } \\
\text { infarction }\end{array}$ & 25 days & 6 & $\begin{array}{c}\text { Myocardial } \\
\text { infarction }\end{array}$ & 17 mont \\
\hline
\end{tabular}

RESULTS

Of the 26 patients, 20 were alive at the time of this review. Of the six deaths, three occurred ino hospital $(11.7 \%)$ and three after discharge. Table III summarizes these, but because the mortalityo is high in comparison with that obtained in younger patients, a brief case report of theses patients is appropriate.

CASE 22 This 56-year-old man was classified as func tional grade IIIB at the time of operation. He waso known to have partial anomalous pulmonary venous connections to the superior vena cava, a persistent left superior vena cava draining to the ooronary sinus, and slight rheumatic aortic incompetence. His pulN monary arterial pressure was only slightly raised (Table I). The difficulties encountered in the repairo of the defect have already been described. Initially his post-operative progress was uneventful. There waso no suggestion of superior vena caval obstruction. Heे required intermittent positive pressure ventilation. He collapsed after about eight hours with cardiac arreste and could not be resuscitated. At necropsy the repair was found to be satisfactory and no ready explana $\frac{T}{2}$ tion for his sudden death was found.

CASE 26 This 59-year-old woman, classified as grade⿻ II before operation (Table I), had a relatively smalb 
secundum atrial septal defect closed by direct suture using the atrial well. Post-operatively she was started on anticoagulants because of a past history of deepvein thrombosis and made excellent progress until the fourth post-operative day, when she became severely shocked following chest pain. An initial diagnosis of pulmonary embolism was made and when it became evident that she had in fact a massive right haemothorax she could not be resuscitated. Post-mortem examination confirmed the presence of a large right haemothorax.

CASE 25 This 58-year-old man, classified as grade IIIA (Table I), had an atrial septal defect in association with mitral incompetence due to a ruptured chord. He also showed the skeletal deformities of the HoltOram syndrome. His defect was successfully closed on cardiopulmonary bypass and a mitral valve plication was performed. Convalescence was uneventful until the 25 th post-operative day, when he complained of sudden severe retrosternal pain. An electrocardiogram showed changes consistent with widespread posterior myocardial infarction. Cardiac arrest occurred 20 minutes later and attempted resuscitation was unsuccessful. At post-mortem examination the circumflex coronary artery was found to be completely occluded by a thrombus.

CASE 18 This 52-year-old man who had chronic bronchial asthma was in functional grade IV. He had a large left-to-right shunt with a moderate increase in pulmonary artery pressure but a pulmonary vascular resistance within the normal range (Table II). A large atrial septal defect was closed with a prosthetic patch on cardiopulmonary bypass. The immediate postoperative course was stormy in that he developed severe bronchospasm, and ventricular fibrillation recurred three times while he was still in the operating theatre. He was defibrillated on each occasion. His sternal wound subsequently required re-suturing and eventually became infected. After two weeks he developed severe congestive heart failure for reasons which were obscure. This was treated intensively with good results and he was eventually discharged free from failure. A post-operative catheter study showed no residual shunt and normal pulmonary artery pressures and resistance (Table II). He died suddenly at home four months post-operatively at a time when his general practitioner considered that he had improved symptomatically. There was no necropsy and death was presumed to be due to an arrhythmia.

CASE 1 This patient was an extremely obese man of 45 . He was classified grade IIIA pre-operatively and had been in congestive heart failure, requiring digitalis and diuretics. He was a heavy drinker and was under treatment for systemic hypertension. Pulmonary function tests showed impaired alveolar ventilation, thought to be secondary to his obesity. There was a relatively small bi-directional shunt, but the pulmonary vascular resistance was significantly raised
(Table I). He was accepted reluctantly for operation and a small secundum defeot with partial anomalous venous connections to the right atrium was completely corrected with a prosthetic patch using the atrial well technique. His subsequent progress was satisfactory, and at his last review 19 months postoperatively, and eight months before his death, he was thought to be so much better that digoxin was stopped and he was allowed to return to work. He apparently deteriorated subsequently and was said to have been 'in and out of cardiac failure' until the time of his death, which was attributed to 'myocardial failure'. A post-montem examination was not performed.

CASE 6 This 47-year-old woman was classified grade II pre-operatively. She had a large shunt but only mildly raised pulmonary arterial pressures (Table I). A modest-sized atrial septal defect was closed by direct suture using the atrial well technique and her convalescence was without incident. Eighteen months later she died after severe retrosternal chest pain. Postmortem examination confirmed the diagnosis of myocardial infarction due to atheromatous coronary artery occlusion. At the time of death she was probably in functional grade $I$.

In summary, three deaths were olosely associated with the operation itself. One of them (case 26) was avoidable, whilst another (case 26) was due to coincidental ischaemic heart disease. Of the three late deaths, one (case 6) was due to ischaemic heart disease, and another (case 1) was attributed to progressive myocardial failure in an obese, hypertensive man of alcoholic habits. Two deaths, one early (case 22) and one late (case 18), appear to have been due to arrhythmia. There was no apparent relationship between the mortality and the functional grading, the size of the lefit-to-right shunt, or pulmonary vascular resistance.

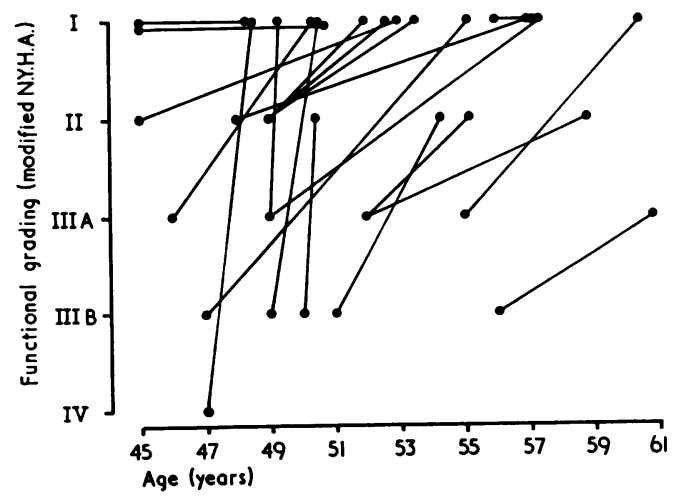

FIG. 3. Change in functional grading of 20 survivors of closure of atrial septal defect during period of follow-up. 


\section{EVALUATION OF SURVIVORS}

Figure 3 illustrates the change in functional grading of these 20 patients. In many cases the improvement has been dramatic. Thirteen are symptom-free. Of the remainder, five admit to some exertional dyspnoea and two to occasional bouts of palpitations. In no case are these symptoms severe or disabling.

Of the five patients now classified as functional grade II or worse, three have pulmonary disease, the severity of which has been established by tests of pulmonary function. One (case 17) has a long past history of recurrent bronchitis and is known to have moderate airways obstruction. There has been an impressive reduction in heart size since operation and we believe that her present symptoms are largely the result of chronic bronchitis. The second (case 20) has widespread bullous emphysema involving the left lung and had had a previous thoracotomy to obliterate the cysts. She is known to have had a trivial shunt postoperatively and remains in atrial fibrillation, refusing rhythm reversion. The third patient (case 24) had been shown to have severe airways obstruction pre-operatively. She also had the highest pulmonary vascular resistance of the whole group (Table II). Post-operatively her exercise tolerance has improved, where previously there had been progressive deterioration.

Of the other two in this group, one had severe congestive heart failure with tricuspid incompetence and has been followed for only five months, and the other is in atrial fibrillation and has angina on effort.

On examination only four of the 20 have detectable residual right ventricular lift. One of these is known to have a small residual shunt, and another has tricuspid regurgitation. In four a grade $1 / 4$ ejection systolic murmur in the pulmonary area is still present. Respiratory variation in splitting of the second sound is normal in 17 patients, including two known to have trivial residual shunts. It is abnormal in three, including two with small residual shunts. No patient now has a tricuspid diastolic murmur.

Radiologically, the heart size, pulmonary arterial dilatation, and pulmonary vascularity have, with two exceptions, decreased in all patients (Fig. 4). One of these (case 13) is known to have a residual shunt but is symptom-free, although her heart size is no smaller than preoperatively. In the other (case 2), who is an alcoholic, normal respiratory variation in the splitting of the second heart sound and pulmonary vascu- lar markings argue for successful closure of the septal defect.

Post-operatively, electrocardiograms confirmed $\vec{\phi}$ that six of the patients were in atrial fibrillation. In four, rhythm reversion using either quinidine ois direct current countershock has been successful. $\vec{\circ}$ One failed to revert, and in the other rhythmreversion has not yet been attempted. Two furthere, patients have a supraventricular tachycardia with variable ventricular responses. The remaining $x$ patients are in sinus rhythm. Figure 5 illustrates the change in $R / S$ ratio in lead $V_{1}$ in theser patients. It will be noted that in only two instancesw has there been no reduction in this ratio. One of these patients has been followed for only four? months, and the other (case 20) has a small resi $\vec{i}$ dual shunt. The mean frontal plane vector isD normal in 16 , indeterminate in one, and $+120 \stackrel{\circ}{\circ}$ $-80^{\circ}$, and $-40^{\circ}$ respectively in the remaining three patients.

The data on the 11 patients catheterized both pre- and post-operatively are summarized in Table II. Two patients were found to have definite but

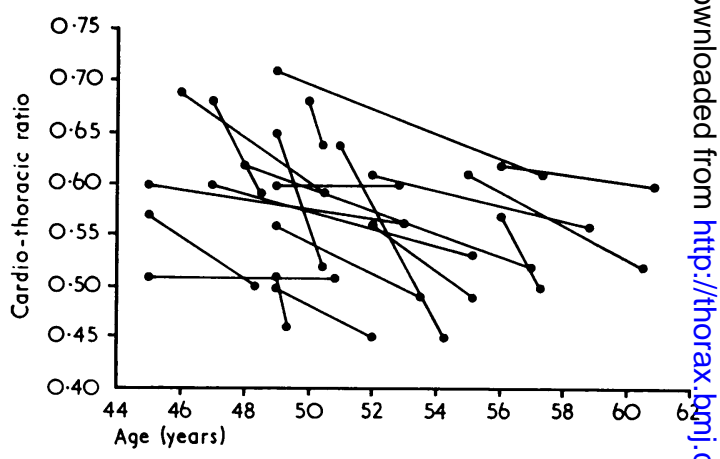

FIG. 4. Change in cardio-thoracic ratio of chest radiograp during period of observation.

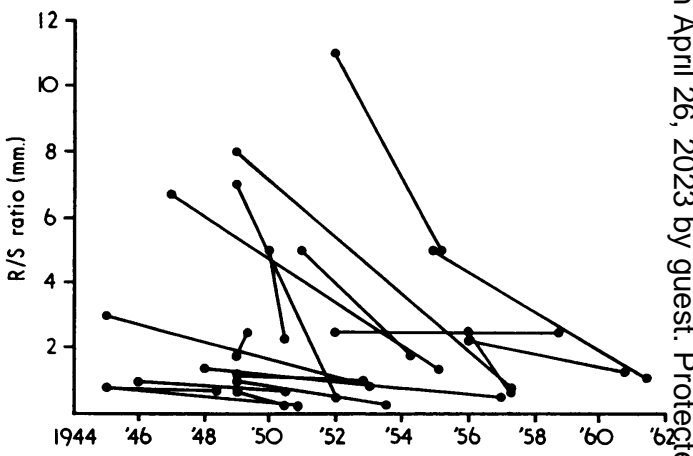

FIG. 5. Change in $R / S$ ratios in lead $V_{1}$ of the electr $\otimes$ cardiogram during follow-up period. 
small residual shunts and one of these was reoperated upon successfully. Three patients have probable trivial residual defects. There has been a substantial fall in pulmonary artery pressure in all cases (Table II), and in all but two, normal levels have been reached. In most cases the pulmonary arteriolar resistance was also normal postoperatively (Table II).

That the pulmonary changes in patients so affected are not always irreversible is demonstrated by the following patient (case 7), a 47 year-old woman, classified grade IV pre-operatively and limited by exertional dyspnoea for many years. On cardiac catheterization pre-operatively, she was found to have a large left-to-right shunt $(\mathrm{Qp} / \mathrm{Qs}=4.5)$ with high pulmonary arterial pressures $(86 / 24$, mean $46 \mathrm{~mm}$. $\mathrm{Hg})$. Respiratory function tests had demonstrated severe airways obstruction. Post-operatively she has improved to the point where she is symptom-free and, although she refused a further catheter study, repeat respiratory function tests indicate considerable improvement since closure of her atrial septal defect 18 months ago.

\section{DISCUSSION}

There is considerable evidence that as patients with an atrial septal defect grow older, they tend increasingly to become symptomatic. Campbell et al. (1957) found that about $50 \%$ of those seen in hospital have symptoms at 40 and more than $75 \%$ at 50 years of age. In their paper, Markman et al. (1965) also showed that the incidence of symptoms increased with advancing age. Under 40 years of age $28.4 \%$ of their patients were experiencing symptoms. Between 40 and 45 years $49.2 \%$ were either dead or symptomatic. Between 46 and 50 years $51 \%$ were affected, with $21 \cdot 3 \%$ dead or severely disabled, and between 51 and 60 years of age $75 \%$, of whom nearly one half were dead or severely disabled, were affected. The authors concluded that beyond the age of 50 operative closure of atrial septal defect is likely to be hazardous because of irreversible changes in the myocardium and lungs. However, only three of their patients had undergone operative repair and their conclusions regarding operation are largely speculative.

Wolf et al. (1968) also question the value of surgical repair of atrial septal defects in persons over the age of 45 . In their experience surgical correction was beneficial mainly to the patients who were symptomatic, with normal or at most mild to moderate increases in pulmonary artery pressure.
Since our review has been completed, Daicoff, Brandenburg, and Kirklin (1967) have reported a clinical follow-up of 155 patients aged 45 to 68 years with atrial septal defects operated upon at the Mayo Clinic. The late results of operation were classed as excellent in $83 \%$ and good in $13 \%$ and their results, when compared with the untreated series of Markman et al. (1965) indicate a significantly longer survival in those patients treated surgically.

Gault, Morrow, Gay, and Ross (1968) have reported their experience of atrial septal defect repair in patients over the age of 40 years. They concluded that operative treatment of atrial septal defect may be undertaken with a relatively low mortality in patients in the fifth decade, despite the presence of pulmonary hypertension, large left-to-right shunts or congestive heart failure. In their series, correction of the defect resulted in sustained clinical and haemodynamic improvement in most patients even when there had been advanced symptomatic disability pre-operatively.

Our experience is comparable to that of both Kirklin's and Ross's groups (Kirklin et al., 1956 ; Gault et al., 1968), for our patients in this age group have been almost invariably improved following successful surgical closure of the atrial septal defect. Of those operated on $50 \%$ are now symptom-free and a further $27 \%$ have been significantly improved. In terms of the functional grading, eight have improved by one, six by two, three by three, and one by four grades. Three patients classified as grade I initially remain in this grade. Radiographic, electrocardiographic, and catheter evidence confirms that the symptomatic improvement is based on underlying haemodynamic improvement. At first sight the mortality appears high and compares unfavourably with a hospital mortality of $1.5 \%$ in 200 patients less than 45 years of age (Barratt-Boyes and Cole, 1967). The deaths, however, include two due to ischaemic heart disease which will always be a hazard in an older group of patients such as this.

The incidence of residual shunts in those restudied is also appreciably greater than in our overall experience (Barratt-Boyes, 1963), although in three of the five it is questionable and clearly trivial, and all these patients are symptomatically improved. There would seem to be no particular reason why the incidence should be greater in this age group, and we suspect it is merely a chance finding in this small series.

The inclusion of patients operated on by Mr. D. Cole is gratefully acknowledged. 


\section{REFERENCES}

Barratt-Boyes, B. G. (1963). The results of repair of atrial septal defect using the atrial well method. Ann. roy. Coll. Surg. Engl., 33, 209.

— and Cole, D. C. (1967). Unpublished data.

Burrett, J. B., and White, P. D. (1945). Large interauricular septal defect with particular reference to diagnosis and longevity. Amer. J. med. Sci., 209, 355.

Campbell, M., Neill, Catherine, and Suzman, S. (1957). The prognosis of atrial septal defect. Brit. med. J., 1, 1375.

Cosby, R. S., and Griffith, G. C. (1949). Interatrial septal defect. Amer. Heart J., 38, 80.

Daicoff, G. R., Brandenburg, R. O., and Kirklin, J. W. (1967). Results of operation for atrial septal defect in patients forty-five years of age and older. Circulation, 35, Suppl. I, p. 143.

Davidsen, H. G. (1960). Atrial Septal Defect. Munksgaard, Copenhagen.

Donald, K. W., Bishop, J. M., and Wade, O. L. (1954). A study of minute to minute changes of arterio-venous oxygen content difference, oxygen uptake and cardiac output and rate of achievement of a steady state during exercise in rheumatic heart disease. J. clin. Invest., 33, 1146.
Gault, J. H., Morrow, A. G., Gay, W. A., Jr., and Ross, J., Jr. (1968) Atrial septal defect in patients over the age of forty years. Clinicaio and hemodynamic studies and the effects of operation. Circula- $\overline{-}$ tion, 37, 261.

Kirklin, J. W., Ellis, F. H., Jr., and Barratt-Boyes, B. G. (1956). Technique for repair of atrial septal defect using the atrial well. Surg. Gynec. Obstet., 103, 646.

Markman, P., Howitt, G., and Wade, E. G. (1965). Atrial septal defect in the middle-aged and elderly. Ouart. J. Med., 34, 409.

Roesler, H. (1934). Interatrial septal defect. Arch. intern. Med., 54, 339:-

Welch, K. J., and Kinney, T. D. (1948). The effect of patent ductus arteriosus and of interauricular and interventricular septal defects on the development of pulmonary vascular lesions. Amer. J. Path. 24, 729.

Williams, J. C. P., and Barratt-Boyes, B. G. (1959). Atrial septal defect: the results of repair using the atrial well method. N.ZN med. J., 58, 279.

Wolf, P. S., Vogel, J. H. K., Pryor, R., and Blount, S. G., Jr. (1968). Atrial septal defect in patients over 45 years of age. Merits of surgical versus medical therapy. Brit. Heart J., 30, 115.

Wood, P. (1962). Diseases of the Heart and Circulation, 2nd ed Eyre and Spottiswoode, London. 